11. Doyle TW, Washko GR, Fernandez IE, Nishino M, Okajima Y, Yamashiro T, Divo MJ, Celli BR, Sciurba FC, Silverman EK, et al. Interstitial lung abnormalities and reduced exercise capacity. Am J Respir Crit Care Med 2012;185:756-762.

12. du Bois RM, Weycker D, Albera C, Bradford WZ, Costabel U, Kartashov A, Lancaster L, Noble PW, Sahn SA, Szwarcberg J, et al. Six-minute-walk test in idiopathic pulmonary fibrosis: test validation and minimal clinically important difference. Am J Respir Crit Care Med 2011;183:1231-1237.
13. Washko GR, Lynch DA, Matsuoka S, Ross JC, Umeoka S, Diaz A, Sciurba FC, Hunninghake GM, San Jose Estepar R, Silverman EK, et al. Identification of early interstitial lung disease in smokers from the COPDGene study. Acad Radiol 2010;17:48-53.

Copyright $\odot 2012$ by the American Thoracic Society

DOI: $10.1164 /$ rccm.201202-0222ED

\title{
Extracorporeal Membrane Oxygenation as "Bridge" to Lung Transplantation: What Remains in Order to Make It Standard of Care?
}

Since its introduction into clinical practice, lung transplantation (LTx) is gradually becoming a worldwide standard treatment for patients with a broad spectrum of end-stage respiratory diseases (1-3). From 1995 to 2010, more than 30,000 LTx have been performed, and it is worth noting that in recent years the number of LTx has been progressively increasing to more than $3,000 /$ year in 2010 , with a post-transplant graft half-life that went from 4.7 in the 1990 s to 5.9 in the new millennium (4). However, the crude mortality rate of patients awaiting LTx is higher than mortality for other solid organs. Mortality rate in 2009 for patients on the waiting list for LTx was about $14.1 \%$ in North America (www.srtr.org) and $14.7 \%$ in Italy (www.airt.it). What are the reasons for these unacceptable mortality rates? First, patients have to wait for the graft longer than patients waiting for other organs because of the small number of lungs suitable for transplantation (5). Second is the lack of supportive therapies that are able to replace respiratory function when the primary pulmonary diseases evolve from "respiratory insufficiency" to "respiratory failure," characterized by refractory hypoxemia and hypercapnia.

\section{HOW TO MANAGE SHORTAGE OF GRAFTS FOR LUNG TRANSPLANTATION}

Different lines of investigation have been developed with the goal of increasing lung suitability from the multiorgan donor. In particular, a recent study demonstrated that a lung-protective mechanical ventilation strategy applied in potential donors might significantly increase the eligibility of the lungs for transplant (6). Moreover, a very innovative technique of ex vivo lung perfusion has been shown effective in a clinical trial examining reconditioning human lungs from high-risk donors, which would have been declined according to conventional criteria (7).

\section{HOW TO "BRIDGE" PATIENTS TO LUNG TRANSPLANTATION}

Invasive mechanical ventilation (IMV), which is usually applied in these cases, may not fulfill the goals of an optimal bridge to LTx. In fact, IMV is a potential cause of ventilator-associated pneumonia and ventilator-induced lung injury, which can further enhance the initial lung damage and lead to multiorgan dysfunction, resulting in clinical unsuitability for LTx ("too sick to be transplanted").

Extracorporeal life support (ECLS), such as extracorporeal membrane oxygenation (ECMO), after initially discouraging experiences, is being progressively recognized as an optimal

Supported by the Italian Ministry of University and Research PRIN 2007 and Fondazione per la Ricerca sulla Fibrosi Cistica-onlus 2008. strategy to bridge patients with lung failure to LTx. In fact, ECLS can potentially provide an adequate level of respiratory support for the patient's requirements, thereby minimizing the clinical impact of mechanical ventilation and increasing the chance to receive a successful LTx $(8,9)$. Although suggested by a number of case reports (10-12), this hypothesis has never been systematically investigated.

In this issue of the Journal (pp. 763-768), the article published by Dr. Fuehner and colleagues is a welcome next step in this line of study (13). The authors reported on the outcome of 26 patients awaiting LTx, who developed end-stage respiratory failure and were supported with ECMO while awake, as bridge to definitive treatment. These data were compared with those of 34 historical control patients, who were supported traditionally with IMV as a bridging treatment to LTx. The results of this study confirmed that ECMO is a very efficient strategy to bridge patients to LTx and, furthermore, suggested that for this purpose ECMO may be even more efficacious than IMV. In fact, although both groups were comparable in terms of duration of support ( 9 d vs. 15 d) and percentage of patients that received LTx (23\% vs. $29 \%$ ), survival at six months after LTx was significantly higher in the ECMO group ( $80 \%$ vs. $50 \%, P=0.02$ ). Therefore, ECMO was as effective as IMV in extending the pretransplant life expectancy to increase the chances to receive an organ, but probably more effective than IMV in preserving physiological homeostasis, thus preserving the post-transplant life expectancy, more closely approaching the ideal "bridge" to LTx.

Remarkably, in this experience ECMO was applied as an alternative to IMV with the declared purpose of avoiding its injurious effects, and not as rescue treatment in patients refractory to conventional therapy. Therefore, it was applied in extubated, awake patients at an earlier stage of their progression to respiratory failure. This strategy may also allow patients to ambulate, receive active physiotherapy, and thus potentially be in better physical condition to ultimately benefit the most from LTx (14). However, in $27 \%$ of cases in the ECMO group, IMV could not be avoided. Interestingly, these patients had a post-LTx survival rate of only $43 \%$. From this data stems the ultimate need to define the optimal timing and clinical criteria to apply ECLS as bridge to LTx. Starting ECLS too early might increase the chance of developing ECLS-related complications, whereas starting too late may not be optimal to prevent multiorgan dysfunction.

The study by Dr. Fuehner and colleagues is particularly provocative as it is the first attempt, as far as bridging to LTx is concerned, to systematically compare ECMO and IMV. Previously, only case series have generally been published (10-12), demonstrating bridging feasibility but without the chance to measure 


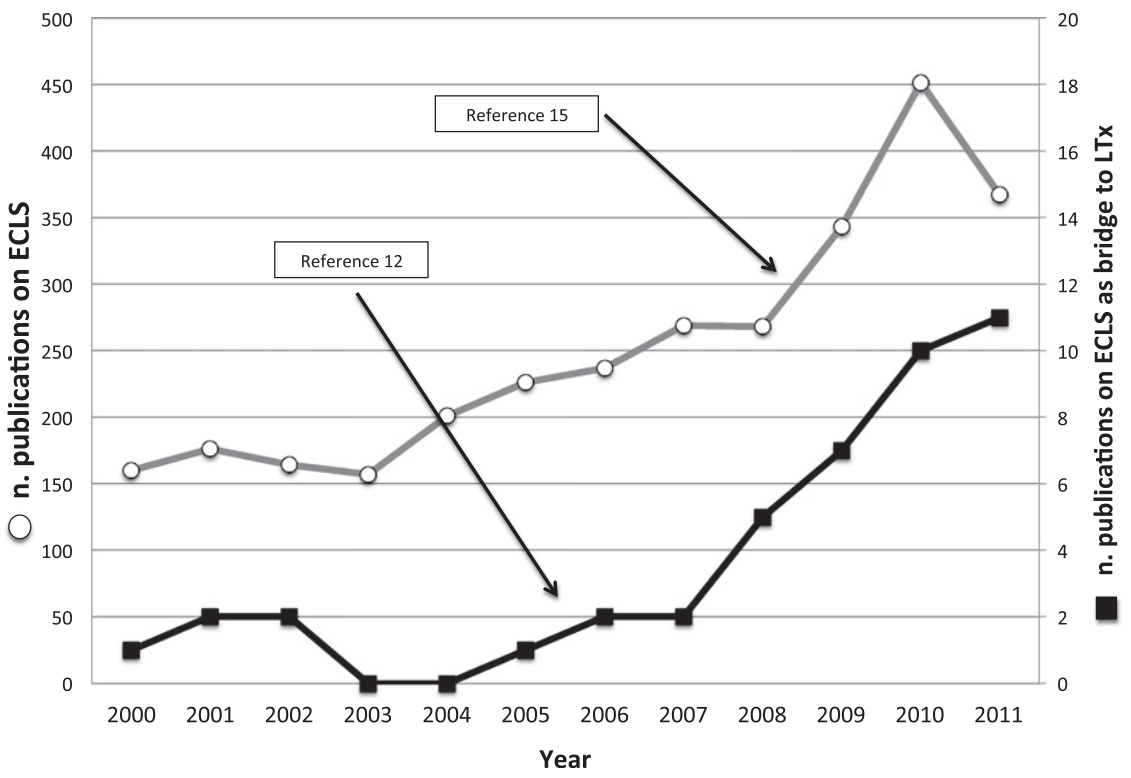

Figure 1. Number of articles on extracorporeal life support (ECLS) (gray line, left vertical axis) and ECLS as bridge to LTx (black line, right vertical axis), published on PubMed for each year from 2000 until 2011. the impact of the results against a control group. This concern has been, at least in part, addressed in this report by identifying historical control patients treated with IMV as bridge to LTx. It is recognized that the comparison is limited in that the historical control patients were nonmatched, and the investigation was only a retrospective observational analysis of few patients, treated in a single center. Although these are relevant methodological issues, the study by Dr. Fuehner and colleagues has the merit of providing a solid background and enticing data for the basis of a multicenter randomized controlled trial (RCT), which is, at this point, strongly warranted. An RCT would ultimately clarify an understanding of whether the potential increased incidence of ECLSrelated complications outweighs the injurious effects of IMV, as a bridge to LTx. This step will be key in defining ECLS as the standard of care in patients with lung failure waiting for transplant.

Are these data sufficient to propose ECLS as standard bridge procedure for patients waiting for lung transplant? In the last decade, there has been a progressive increase in the literature of publications on ECLS (see Figure 1), including ECLS as bridge to LTx. Interestingly, a relevant increase in publications is generally observed in coincidence with two episodes: (1) the H1N1 epidemics (15), and (2) coincident technological advances in ECLS $(12,16)$. This may explain why only very few RCTs have been published on ECLS for patients with respiratory failure, and no RCTs have been performed on strategies to bridge to LTx.

In our view, the current extensive clinical efforts to improve the efficacy of the supportive treatments bridging patients to LTx should adopt the methodological challenges taken by the studies that have tested strategies aiming at increasing the number of suitable lungs for transplant from multiorgan donors (6). We acknowledge the difficulties of randomizing patients in end-stage respiratory failure waiting for a transplant, but ultimately clinicians need to have more solid evidence than that provided by Fuehner and colleagues. Alternative methods, including pragmatic study design and cluster randomization procedure, may provide information about ECLS. The technology of mechanical ventilation has evolved and continued to improve over time, and strategies of protective lung ventilation have improved the performance of mechanical ventilation to support critically ill patients. Also, ECLS, which was historically a costly and imperfect technology with significant morbidity, has advanced technologically and come of age-with better performance and an improved morbidity profile. It is now theoretically truly conceivable to consider that ECLS may be more effective and have less overall morbidity in patients with advanced lung failure. It is time to compare these two technologies head to head in an RCT.

Author disclosures are available with the text of this article at www.atsjournals.org.

Lorenzo Del Sorbo, M.D.

V. Marco Ranieri, M.D.

Dipartimento di Anestesiologia e Medicina degli Stati Critici Università di Torino

Torino, Italy

Shaf Keshavjee, M.D.

Toronto Lung Transplant Program

University of Toronto

Toronto, Canada

\section{References}

1. Cooper JD, Pearson FG, Patterson GA, Todd TR, Ginsberg RJ, Goldberg M, DeMajo WA. Technique of successful lung transplantation in humans. J Thorac Cardiovasc Surg 1987;93:173-181.

2. Kotloff RM, Thabut G. Lung transplantation. Am J Respir Crit Care Med 2011;184:159-171.

3. Pierre AF, Keshavjee S. Lung transplantation: donor and recipient critical care aspects. Curr Opin Crit Care 2005;11:339-344.

4. Christie JD, Edwards LB, Kucheryavaya AY, Benden C, Dobbels F, Kirk R, Rahmel AO, Stehlik J, Hertz MI. The Registry of the International Society for Heart and Lung Transplantation: twenty-eighth adult lung and heart-lung transplant report-2011. J Heart Lung Transplant 2011;30:1104-1122.

5. Punch JD, Hayes DH, LaPorte FB, McBride V, Seely MS. Organ donation and utilization in the United States, 1996-2005. Am J Transplant 2007:7:1327-1338.

6. Mascia L, Pasero D, Slutsky AS, Arguis MJ, Berardino M, Grasso S, Munari M, Boifava S, Cornara G, Della Corte F, et al. Effect of a lung protective strategy for organ donors on eligibility and availability of lungs for transplantation: a randomized controlled trial. JAMA 2010;304:2620-2627.

7. Cypel M, Yeung JC, Liu M, Anraku M, Chen F, Karolak W, Sato M, Laratta J, Azad S, Madonik M, et al. Normothermic ex vivo lung perfusion in clinical lung transplantation. N Engl J Med 2011;364:1431-1440.

8. Cypel M, Keshavjee S. Extracorporeal life support as a bridge to lung transplantation. Clin Chest Med 2011;32:245-251.

9. Del Sorbo L, Boffini M, Rinaldi M, Ranieri VM. Bridging to lung transplantation by extracorporeal support. Minerva Anestesiol 2012;78:243-250. 
10. Bermudez CA, Rocha RV, Zaldonis D, Bhama JK, Crespo MM, Shigemura N, Pilewski JM, Sappington PL, Boujoukos AJ, Toyoda Y. Extracorporeal membrane oxygenation as a bridge to lung transplant: midterm outcomes. Ann Thorac Surg 2011;92:1226-1232.

11. Jackson A, Cropper J, Pye R, Junius F, Malouf M, Glanville A. Use of extracorporeal membrane oxygenation as a bridge to primary lung transplant: 3 consecutive, successful cases and a review of the literature. J Heart Lung Transplant 2008;27:348-352.

12. Fischer S, Simon AR, Welte T, Hoeper MM, Meyer A, Tessmann R, Gohrbandt B, Gottlieb J, Haverich A, Strueber M. Bridge to lung transplantation with the novel pumpless interventional lung assist device NovaLung. J Thorac Cardiovasc Surg 2006;131:719-723.

13. Fuehner T, Kuehn C, Hadem J, Wiesner O, Gottlieb J, Tudorache I, Olsson KM, Greer M, Sommer W, Welte T, et al. Extracorporeal membrane oxygenation in awake patients as bridge to lung transplantation. Am J Respir Crit Care Med 2012;185:763-768.
14. Turner DA, Cheifetz IM, Rehder KJ, Williford WL, Bonadonna D, Banuelos SJ, Peterson-Carmichael S, Lin SS, Davis RD, Zaas D. Active rehabilitation and physical therapy during extracorporeal membrane oxygenation while awaiting lung transplantation-a practical approach. Crit Care Med 2011;39:2593-2598.

15. Davies A, Jones D, Bailey M, Beca J, Bellomo R, Blackwell N, Forrest P, Gattas D, Granger E, Herkes R, et al. Extracorporeal membrane oxygenation for 2009 influenza A (H1N1) acute respiratory distress syndrome. JAMA 2009;302:1888-1895.

16. Maclaren G, Combes A, Bartlett RH. Contemporary extracorporeal membrane oxygenation for adult respiratory failure: life support in the new era. Intensive Care Med 2012;38:210-220.

Copyright $\odot \mathbf{2 0 1 2}$ by the American Thoracic Society DOI: 10.1164/rccm.201202-0193ED 